\title{
Overdiagnostikk av brystkreft etter 14 år med mammografiscreening
}

\author{
Engelsk oversettelse på www.tidsskriftet.no
}

\begin{abstract}
Sammendrag
Bakgrunn. I 2004 skrev vi i Tidsskriftet at mammografiscreening medførte massiv overdiagnostikk og overbehandling av brystkreft. Vår studie ble kritisert fordi vi bare hadde en oppfølgingstid på fem år og ikke tok hensyn til at økt bruk av hormoner mot plager i overgangsalderen kunne føre til mer brystkreft. Vi har nå fulgt kvinner i 14 år med screening, i en periode hvor hormonbruken har falt med $70 \%$.
\end{abstract}

Materiale og metode. Aldersspesifikke insidensrater, deteksjonsrater og intervallkreftrater for brystkreft i perioden 1991-2009 er beregnet for 40-79 år gamle kvinner. Insidenstrender er beregnet med Poisson-regresjon.

Resultater. Brystkreftinsidensen i aldersgruppen 40-49 år var stabil i hele perioden, men insidensen steg med $50 \%$ i aldersgruppen 50-69 år umiddelbart etter screeningstart. Det var ingen signifikant reduksjon i brystkreftinsidens i aldersgruppen 70-74 år. Antall nye brystkrefttilfeller i perioden økte fra rundt 2000 til 2750 . I tillegg ble rundt 300 tilfeller av duktalt carcinoma in situ (DCIS) diagnostisert. Til sammen er det nå årlig rundt 1050 flere kvinner som blir diagnostisert enn det var før screeningen startet. Våre beregninger tyder på at i fravær av screening ville rundt 800 av disse kvinnene aldri ha blitt brystkreftpasienter.

Fortolkning. Tallene fra 14 år med mammografiscreening tyder på at all $ø$ kning i brystkreftinsidens skyldes overdiagnostikk - påvisning av svulster som i fravær av screening aldri ville ha gitt opphav til klinisk sykdom.

\section{Per-Henrik Zahl}

per-henrik.zahl@fhi.no

Divisjon for epidemiologi

Nasjonalt folkehelseinstitutt

\section{Jan Mæhlen}

Patologisk-anatomisk avdeling

Oslo universitetssykehus, Ullevål

Insidensen av brystkreft i Norge har økt de siste 50 år (1). Økningen har vært spesielt sterk etter 1995 og rammet da i hovedsak aldersgruppen 50-69 år (2). I 1996 ble det startet organisert mammografiscreening for aldersgruppen 50-69 år i Akershus, Oslo, Rogaland og Hordaland (prøvefylkene). Sammenliknet med perioden 1991-95 var brystkreftinsidensen i den inviterte aldersgruppen 82\% høyere i 1996-97 (første screeningrunde) og 50\% høyere i 1998-2000 (andre og tredje screeningrunde) (2). I tillegg ble et stort antall tilfeller av duktalt carcinoma in situ (DCIS) oppdaget ved mammografi (3). Vi beregnet at man etter at screening var innført over hele landet ville få 770 flere brystkreftdiagnoser årlig (3).

Det har vært vanlig å anta at den primære årsaken til økningen i brystkreftinsidens hos kvinner som møter til screening er at noen kreftdiagnoser fremskyndes og at det senere kommer et insidensfall. «Lead time» (tidsforskyvning) er et begrep som brukes for å angi hvor mye man tror diagnosetidspunktet er blitt fremskyndet. Begrepet er imidlertid forvirrende når man har svulster som i fravær av screening aldri ville ha blitt diagnostisert (enten fordi de ikke vokser eller fordi de blir borte av seg selv). For slike svulster gir «tidsforskyvning» ingen mening.

Overdiagnostisering ved kreftscreening kan defineres som påvisning av svulster som ellers aldri ville ha blitt oppdaget i pasientens levetid (4). Overdiagnostikk er (i motsetning til tidsforskyvning/lead time) definert for alle svulster som diagnostiseres ved mammografi og er lett å regne ut. Det absolutte antall overdiagnostiserte kvinner regnes ut ved å ta differansen mellom økningen $\mathrm{i}$ antall kreftdiagnoser hos dem som inviteres til screening (i forhold til forventet antall for aldersgruppen) og reduksjonen i antall diagnoser hos dem som ikke lenger inviteres.

Vi har tidligere påpekt at fordi det ikke er noen sikker reduksjon $\mathrm{i}$ brystkreftinsidens $\mathrm{i}$ aldersgruppen over 70 år, så må tilnærmet hele økningen på $50 \%$ i aldersgruppen 50-69 år være overdiagnostikk (2). At det i samme periode var tilnærmet stabil brystkreftinsidens i aldersgruppen 40-49 år (som ikke inviteres til screening), taler imot at økningen i stedet skyldes generelt økende brystkreftinsidens hos norske kvinner (2). Vi konkluderte derfor med at én av tre brystkrefttilfeller i aldersgruppen 50-69 år er overdiagnostisert svulstsykdom (2). Av de øvrige brystkrefttilfellene (som ikke er overdiagnostisert) utgjøres mer enn halvparten av intervallkreft (kreft som oppdages mellom to screeningrunder) og av svulster som diagnostiseres hos de $20-25 \%$ av de inviterte som velger ikke å møte opp til screening. Det blir dermed tilsvarende færre reelle krefttilfeller igjen som kan oppdages ved screening. Vi har tidligere vist at når man inkluderer duktalt carcinoma in situ og ser bort fra intervallkreft og kreft hos dem som ikke går til screening, må hele to av tre kreftdiagnoser (inkludert DCIS-diagnoser) i mammografiscreeningen representere overdiagnostikk.

Hvis tidlig diagnostikk skulle være årsak til 770 flere kreftdiagnoser i aldersgruppen 50-69 år, så må det komme et svært dramatisk fall etter 69 års alder (5). I aldersgruppen 70-84 år er det for eksempel bare ca. 450 tilfeller av brystkreft i året (1). Vi har tidligere rapportert at det ikke kom noen statistisk sikker reduksjon i brystkreftinsidens i denne aldersgruppen (2). Vi har i stedet foreslått at screening fører til massiv overdiagnostikk og at overdiagnostiserte svulster normalt (dvs. i fravær av screening) vil forsvinne av seg selv $(6,7)$.

En viktig innvending mot vår studie $\mathrm{i}$ 2004 var at med bare tre screeningrunder hadde vi for kort oppfølgingstid til å kunne si noe sikkert om nivået av overdiagnostikk. En annen innvending var at vi ikke justerte for økt bruk av hormoner mot plager i overgangsalderen. Vi har derfor nå oppdatert vårt estimat av overdiagnostikk med data fra sju screeningrunder.

\section{Hovedbudskap}

- Mammografiscreening forklarer i en statistisk analyse all insidensøkning av brystkreft

- Mammografiscreening har medført at 800 flere kvinner årlig blir behandlet for brystkreft 


\begin{tabular}{|c|c|c|c|c|c|c|c|c|c|c|c|c|}
\hline & 1998 & 1999 & 2000 & 2001 & 2001 & 2003 & 2004 & 2005 & 2006 & 2007 & 2008 & 2009 \\
\hline Brystkreftrate & 309 & 288 & 288 & 307 & 284 & 318 & 294 & 318 & 286 & 290 & 282 & 293 \\
\hline \multirow[t]{2}{*}{ Duktalt carcinoma in situ } & 50 & 40 & 52 & 48 & 53 & 39 & 51 & 51 & 49 & 50 & 53 & -1 \\
\hline & \multicolumn{2}{|c|}{ (2. runde) } & \multicolumn{2}{|c|}{ (3. runde) } & \multicolumn{2}{|c|}{ (4. runde) } & \multicolumn{2}{|c|}{ (5. runde) } & \multicolumn{2}{|c|}{ (6. runde) } & \multicolumn{2}{|c|}{ (7. runde) } \\
\hline Intervallkreftrate & \multicolumn{2}{|c|}{93} & \multicolumn{2}{|c|}{83} & \multicolumn{2}{|c|}{100} & \multicolumn{2}{|c|}{89} & \multicolumn{2}{|c|}{-1} & \multicolumn{2}{|c|}{-1} \\
\hline Deteksjonsrate & \multicolumn{2}{|c|}{565} & \multicolumn{2}{|c|}{622} & \multicolumn{2}{|c|}{607} & \multicolumn{2}{|c|}{590} & \multicolumn{2}{|c|}{639} & \multicolumn{2}{|c|}{618} \\
\hline
\end{tabular}

\section{Materiale og metode}

Aggregerte data om insidens av infiltrerende brystkreft og duktalt carcinoma in situ diagnostisert i det nasjonale mammografiprogrammet og utenfor programmet er utlevert fra Kreftregisteret. Antall kvinner med risiko for brystkreft hvert år i perioden 1991-2009 er bestemt ved middelfolkemengden som er registrert hos Statistisk sentralbyrå (8).

For å bestemme overdiagnostikknivået har vi benyttet en Poisson-regresjonsmodell til å beregne en eventuell underliggende økning $\mathrm{i}$ brystkreftinsidens for aldersgruppen 40-79 år (vi la inn en lineær trendparameter for hele perioden) mens vi simultant justerte for alder, fylke, befolkningsvekst og innføring av mammografiscreening.

\section{Resultater}

Tabell 1 viser raten av infiltrerende brystkreft, intervallkreft, deteksjonsraten og raten av duktalt carcinoma in situ for kvinner som ble invitert til mammografiscreening i perioden 1998-2009 i de fire prøvefylkene. Både raten av intervallkreft og deteksjonsraten er tilnærmet konstante i dette materialet. Dermed må også insidensen av brystkreft totalt være konstant hos kvinner som går til mammografiscreening. Fordi fallet $\mathrm{i}$ antall fremmøtte er ubetydelig, må insidensen av brystkreft blant inviterte som ikke går til mammografiscreening også være tilnærmet konstant. Det er heller ingen signifikant fallende trend $i$ raten av duktalt carcinoma in situ, verken i prøvefylkene $(\mathrm{p}>0,05)$ eller i resten av Norge $(p>0,05)($ tab 1$)$.

Figur 1 viser insidensrater for brystkreft $i$ perioden 1991-2009 i prøvefylkene. Data fra første screeningrunde (1996-97) er ikke tatt med. Gjennomsnittlig insidensrate i aldersgruppen 50-69 år for hver screeningrunde er henholdsvis 297 (1998-99), 298 (2000-01), 301 (2002-03), 306 (2004-05), 286 (2006-07) og 282 (2008-09) per 100000 kvinner. I perioden 1998-2009 sank insidensraten i aldersgruppen 50-69 år i prøvefylkene med $0,7 \%$ per år $(p=0,064)$. For aldersgruppen 50-59 år sank insidensraten med $1,7 \%(\mathrm{p}<0,001)$ per år. Regresjonsanalysen viser ingen signifikante forandringer $\mathrm{i}$ insidensraten $\mathrm{i}$ aldersgruppene 40-49 år i perioden $1991-2009(\mathrm{p}=0,50)$, men insidensraten i aldersgruppen 70-79 år falt med $1,3 \%$ per år $(\mathrm{p}<0,001)$ i samme periode. Nesten hele reduksjonen er i aldersgruppen 70-74 år, hvor insidensraten falt med 2,4\% per år $(\mathrm{p}=0,02)$ etter 1997.

En Poisson-regresjonsanalyse som inkluderer alder, underliggende trend og innføring av mammografiscreening i 1996 som variabler, viser at kvinner i aldersgruppen 70-74 år som hadde vært invitert til screening da de var yngre, har $7 \%$ lavere insidensrate enn kvinner som ikke var blitt invitert, men denne forskjellen var ikke statistisk signifikant $(\mathrm{p}=0,18)$. Dette fallet tilsvarer rundt ti færre brystkrefttilfeller i året. Innføringen av mammografiscreening i 1996 gjenstår dermed som eneste forklaring på forandringen i brystkreftinsidens i perioden 1991-2009 i prøvefylkene - 50\% økning i brystkreftinsidens i aldersgruppen 50-69 år og et ubetydelig, kortvarig og ikke-signifikant insidensfall etter 69 år.

Ratene for duktalt carcinoma in situ er en indikator på i hvor stor grad kvinner går til screening. Figur 2a viser insidensrater for brystkreft og duktalt carcinoma in situ før og etter start av screening i prøvefylkene. DCIS-ratene var ni (1993), 14 (1994) og 12
(1995) per 100000 . Etter screeningstart vokste raten umiddelbart til 50 per 100000 . Figur $2 \mathrm{~b}$ viser insidensrater for brystkreft og duktalt carcinoma in situ i resten av Norge. DCIS-raten økte fra åtte per 100000 før 1996 til ca. 17 per 100000 i 1998. Da alle de øvrige norske fylkene hadde fått etablert organisert screening, hadde DCIS-raten i disse fylkene nådd ca. 35 per 100000 .

I årene 1991-95 var det i gjennomsnitt 2000 brystkrefttilfeller i Norge. I 1996, som var første år med mammografiscreening, ble det oppdaget 2352 tilfeller. Samme år ble det også diagnostisert 87 DCIS-tilfeller i prøvefylkene, hvorav 48 i screeningprogrammet. I 2009 ble det diagnostisert brystkreft hos 2745 kvinner. I tilegg blir i gjennomsnitt rundt 300 kvinner årlig diagnostisert med duktalt carcinoma in situ.

Fra 1991 til 2009 økte antall kvinner i aldersgruppen 50-69 år med 35\%, fra 403958 til 542852 . I begynnelsen av 1990årene var det årlig ca. 700 brystkrefttilfeller i aldersgruppen 50-69 år. Med uendret insidensrate skulle man for denne aldersgruppen forvente ca. 945 brystkrefttilfeller i 2009 , men Kreftregisteret registrerte 1473 tilfeller

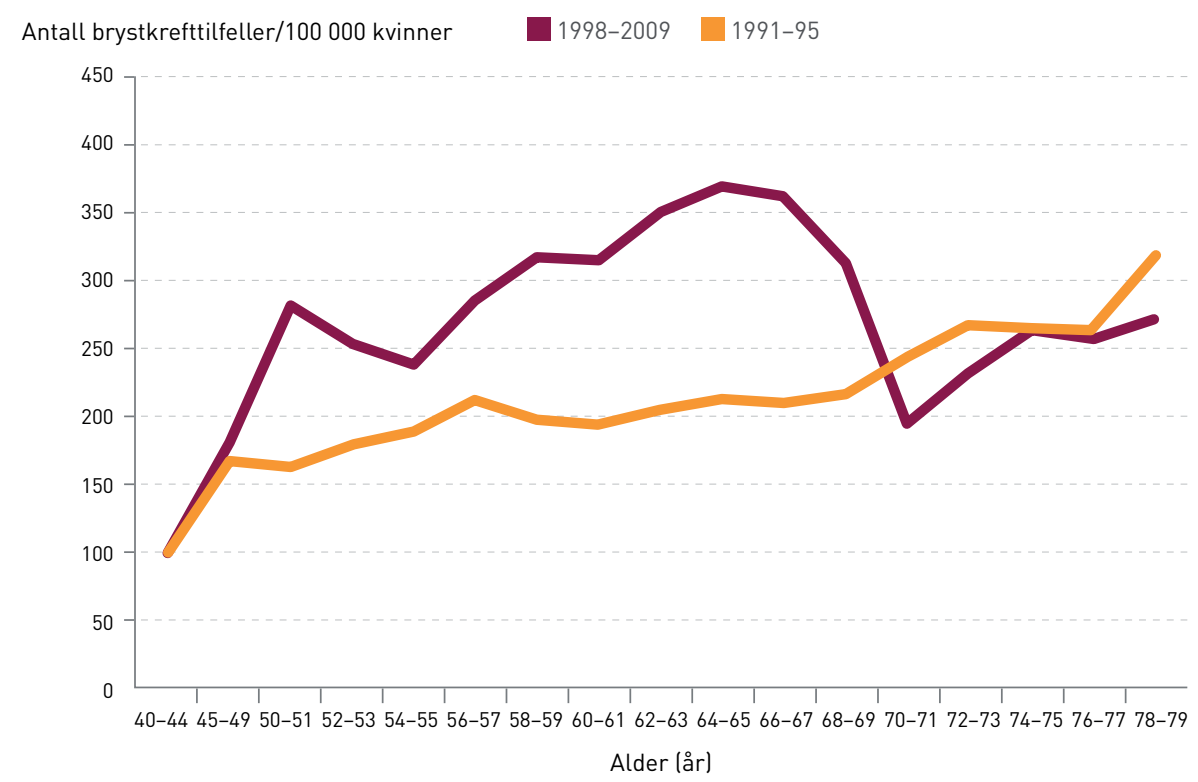

Figur 1 Aldersspesifikk insidens av invasiv brystkreft i prøvefylkene i perioden 1998-2009 (rød linje) og i perioden 1991-95 (gul linje). Merk at de to første aldersgruppene er femårige (40-44 år og 45-49 år) og at aldersgruppene er toårige fra og med 50 år 
a

Antall brystkrefttilfeller/100 000 kvinner

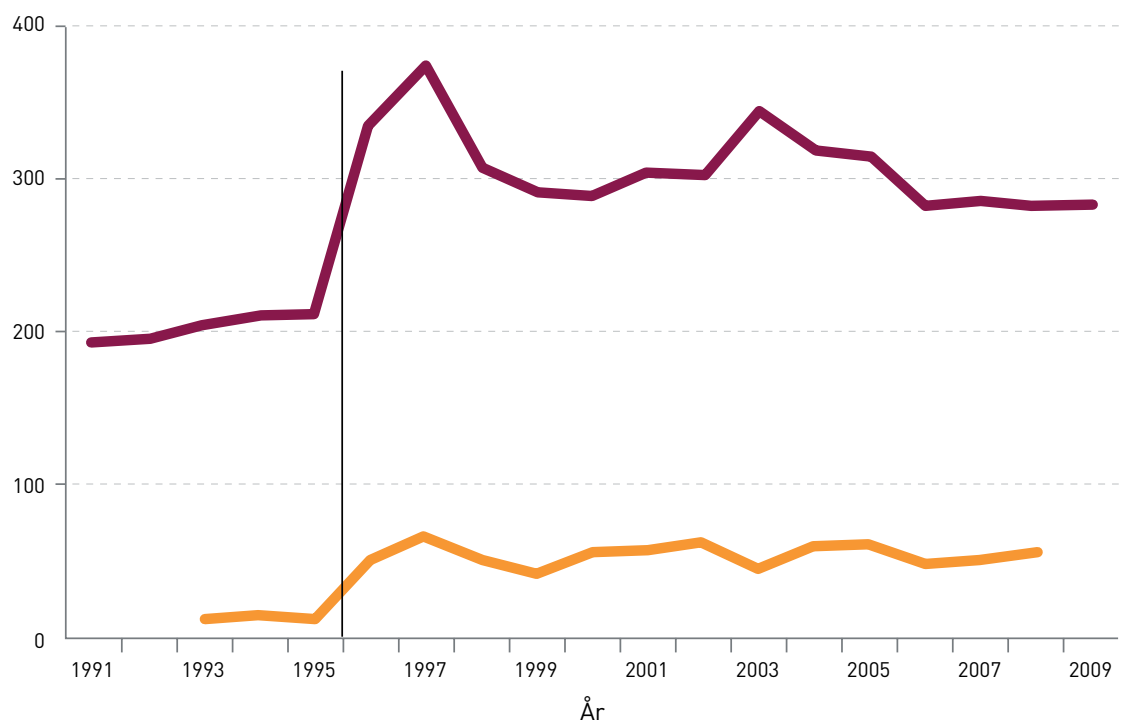

b

Antall brystkrefttilfeller/100 000 kvinner 400

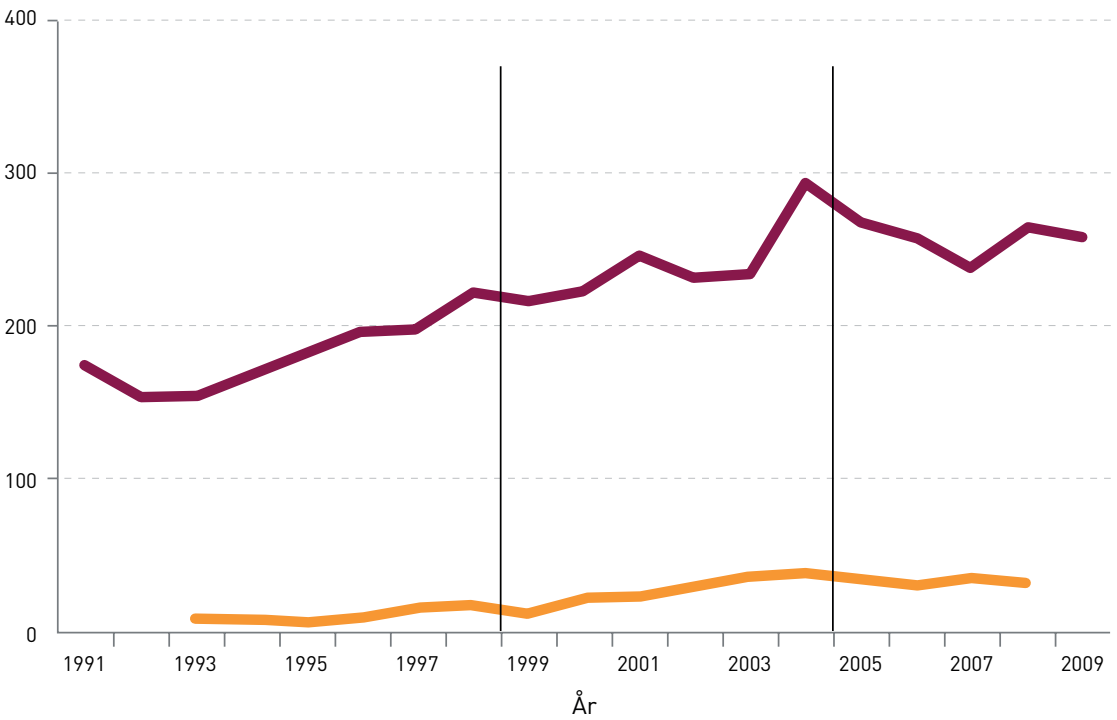

Figur 2 a) Insidens av brystkreft (rød linje) og duktalt carcinoma in situ (gul linje) i prøvefylkene i aldersgrup pen 50-69 år. Den vertikale linjen markerer screeningstart. b) Insidens av brystkreft (rød linje) og duktalt carcinoma in situ (gul linje) i øvrige norske fylker i aldersgruppen 50-69 år. De to vertikale linjene viser tidsperioden da screening ble igangsatt (1999-2004)

dette året. Etter at screeningprogrammet er blitt landsdekkende, blir det dermed i den inviterte aldersgruppen årlig påvist mer enn 500 ekstra brystkrefttilfeller og rundt 300 DCIS-tilfeller. I aldersgruppen 70-74 år er det bare rundt ti færre krefttilfeller årlig. Reduksjonen etter 69 år er ikke signifikant, og man kan diskutere om man skal justere for dette eller ikke. Ti færre brystkrefttilfeller i aldersgruppen over 69 år forklarer imidlertid bare $2 \%$ av den forutgående økningen. En justering for dette har ingen betydning.

\section{Diskusjon}

Etter 14 år med screening i prøvefylkene ligger nå brystkreftinsidensen hos de inviterte stabilt på et nivå som er 50\% over utgangsnivået fra perioden før screeningen startet. Det er ikke blitt noen statistisk signifikant reduksjon i brystkreftinsidens hos kvinner som ikke lenger inviteres til screening. Hadde fallet på 7\% i aldersgruppen 70-74 år vært statistisk signifikant, hadde det bare kunnet forklare et par prosent av økningen på $50 \%$ (2). Dermed må nesten all økning i brystkreftinsidens skyldes overdiagnostisering - ikke tidligdiagnostisering.

Vår regresjonsanalyse av data fra prøvefylkene viser at introduksjonen av screeningprogrammet forklarer all insidensøkning i prøvefylkene for perioden 1991-2009. At vi ikke finner tegn til økning i insidensraten i aldersgrupper som ikke screenes, taler klart imot at det er noen generell underliggende insidensøkning som er uavhengig av hormonbruk (se nedenfor). Vi vil fremheve at datasettet vi har studert, er fra en populasjon med liten migrasjon og med stabilt høyt nivå av fremmøte til screening, stabil deteksjonsrate ved screening, stabil insidens av intervallkreft og stabil brystkreftinsidens hos dem som ikke møter til screening (tab 1).

I en systematisk oversikt av en rekke nasjonale screeningprogrammer fant Jørgensen \& Gøtzsche (9) at brystkreftinsidensen (inkludert duktalt carsinoma in situ) økte med $52 \%$. For Norge beskriver de et lavere nivå av overdiagnostikk enn det vi rapporterer her, men deres analyse er basert på en ekstrapolering av underliggende insidensøkning i prøvefylkene fra perioden 1980-95 (før organisert screening startet). Fordi mye av økningen i denne perioden kan forklares med uorganisert screening, mener vi at de beregner altfor høye verdier av en screeninguavhengig insidensøkning. Konstante eller fallende brystkreftrater $i$ alle vestlige land etter år 2000 for alle aldersgrupper tyder heller ikke på at det ville ha vært noen insidensvekst i fravær av screening (10-13).

I perioden 1991-99 var det en sterk økning $i$ antallet kvinner som brukte hormoner mot plager i overgangsalderen. Senere har antall brukere falt minst like sterkt (13). Årsaken til dette fallet kan tilskrives publisering av randomiserte studier som viste at brystkreftrisikoen økte med $24 \%$ ved langvarig hormonbruk (14). Fra noen land kom det deretter rapporter om at fallet i bruk av hormoner ble etterfulgt av et lite fall i brystkreftinsidens (10-12). I 2007-09 var de norske salgstallene for østrogenpreparater for systemisk behandling (ATC-gruppe G03C og G03F) på rundt $60000 \mathrm{DDD} / \mathrm{dag}$, som er det samme som i perioden 1991-93 (15). I denne perioden har imidlertid antallet potensielle brukere (dvs. kvinner i aldersgruppen 50-69 år) økt med 33\% (8). Det betyr at det i slutten av studieperioden var en langt lavere andel østrogenbrukere enn i starten. At brystkreftinsidensen (justert for mammografiscreening) har holdt seg stabil i hele perioden (og spesielt de siste åtte årene da salget av østrogenpreparater har sunket med $70 \%$ ), tyder på at bruk av østrogener ikke kan være noen særlig viktig årsak til brystkreft i Norge (10).

I flere norske fylker kom det en sterk økning i insidensen av brystkreft før den organiserte screeningen startet. En samtidig økning i DCIS-ratene i disse fylkene (16) kan tyde på at mye av denne økningen skyldes uorganisert screening (diagnosen duktalt carcinoma in situ kan nesten utelukkende stilles etter bruk av mammografi) (17). Vi kan imidlertid ikke utelukke at økt oppmerksomhet omkring brystkreft hos kvinner og leger har ført til flere diagnostiske mammografiundersøkelser, noe som har økt insidensen av både duktalt carcinoma in situ og 
kreft. Dette illustrerer at det er vanskelig å definere hva som skyldes økt oppmerksomhet omkring brystkreft og hva som skyldes uorganisert screening.

I Norge har brystkreftinsidensen sunket litt i aldersgruppen 50-69 år etter 2001, men bare i de fylkene der man innførte screening i perioden 2000-04 (10). Dette fallet kan derfor forklares som en prevalenseffekt - man forventer høyere brystkreftinsidens i første screeningrunde enn i de neste rundene (5).

Overdiagnostikk er vanligvis blitt forklart med påvisning av svulster som vokser så sakte at kvinnene vil dø av andre årsaker før svulstene gir kliniske symptomer $(5,18)$. Slike langsomtvoksende svulster skulle $i$ stor grad bli luket ut når kvinner går til den første runden med screening, og deteksjonsraten skulle synke dramatisk fra første til andre screeningrunde fordi denne svulstpopulasjonen da ville være fjernet. Likeledes skulle insidensraten holde seg meget lavt $i$ mange år fremover når kvinner forlater screeningprogrammet ved 69 års alder (se vårt argument innledningsvis om at det knapt skal være kreft i aldergruppen 70-84 år hvis brorparten av økningen ved screening er tidligdiagnostikk) $(5-7,19)$. Men slik er det ikke! Vi har derfor foreslått at overdiagnostikk i all hovedsak kan forklares med deteksjon av svulster som etter noen tid ville ha gått $\mathrm{i}$ spontan regresjon uten behandling $(6,7)$. Fryback og medarbeidere (19) kom til samme konklusjon da de analyserte kreftregisterdata fra Wisconsin i USA.

\section{Konklusjon}

Etter 14 år med mammografiscreening i prøvefylkene er det en $50 \%$ økning i brystkreftinsidens som ikke kan forklares med tidligdiagnostikk eller bruk av østrogenpreparater. Økningen må i stedet i all hovedsak skyldes overdiagnostikk. Dette betyr at det i Norge hvert år er rundt 800 kvinner som får en unødvendig kreftdiagnose og som dermed gis kreftbehandling (strålebehandling, cellegift og hormonbehandling) uten å ha noen nytte av det.

Ansvarsbegrensning: I denne studien er det brukt data fra Kreftregisteret. Tolking og rapportering av disse dataene er forfatternes ansvar alene og har ikke vært gjenstand for godkjenning fra Kreftregisteret.

\section{Per-Henrik Zahl (f. 1961)}

er dr.med. i biostatistikk og arbeider som statistiker ved Nasjonalt folkehelseinstitutt. Han har publisert flere artikler om mammografiscreening og brystkreftdødelighet.

Ingen oppgitte interessekonflikter.

\section{Jan Mæhlen (f. 1952)}

er overlege i nevropatologi ved Oslo universitetssykehus, Ullevål, professor II ved Universitetet i Oslo og medisinsk konsulent ved Dødsårsaksregisteret, Nasjonalt folkehelseinstitutt. Ingen oppgitte interessekonflikter.

\section{Litteratur}

1. Cancer in Norway 2009. Oslo: Kreftregisteret 2011

2. Zahl PH, Strand BH, Mæhlen J. Incidence of breast cancer in Norway and Sweden during introduction of nationwide screening: prospective cohort study. BMJ 2004: 328: 921 -

3. Zahl PH, Mæhlen J. Overdiagnostisering ved mammografiscreening. Tidsskr Nor Lægeforen 2004; 124: 2238-9.

4. Etzioni R, Urban N, Ramsey S et al. The case for early detection. Nat Rev Cancer 2003: 3: 243-52.

5. Boer R, Warmerdam $\mathrm{P}$, de Koning $\mathrm{H}$ et al. Extra incidence caused by mammographic screening. Lancet 1994; 343: 979.

6. Zahl PH, Mæhlen J, Welch HG. The natural history of invasive breast cancers detected by screening mammography. Arch Intern Med 2008; 168 2311-6.

7. Zahl PH, Gøtzsche PC, Mæhlen J. Natural history of breast cancers detected in the Swedish mammography screening programme: a cohort study. Lancet Oncol 2011; 12: 1118-24.

8. Statistisk sentralbyrå. http://statbank.ssb.no/ statistikkbanken (29.8.2011).

9. Jørgensen KJ, Gøtzsche PC. Overdiagnosis in publicly organised mammography screening pro grammes: systematic review of incidence trends. BMJ 2009; 339: b2587.

10. Suhrke P. Mæhlen J, Zahl PH. Hormone therapy use and breast cancer incidence by histological subtypes in Sweden and Norway. The Breast Journal 2012; akseptert for publisering.

11. Ravdin PM, Cronin KA, Howlader N et al. The decrease in breast-cancer incidence in 2003 in the United States. N Engl J Med 2007; 356: 1670-4.

12. Parkin DM. Is the recent fall in incidence of postmenopausal breast cancer in UK related to changes in use of hormone replacement therapy? Eur J Cancer 2009; 45: 1649-53.

13. Hemminki E, Kyyrönen P. Pukkala E. Postmenopausal hormone drugs and breast and colon cancer: Nordic countries 1995-2005. Maturitas 2008; 61: 299-304

14. Chlebowski RT, Hendrix SL, Langer RD et al. Influence of estrogen plus progestin on breast cancer and mammography in healthy postmenopausal women: the Women's Health Initiative Randomized Trial. JAMA 2003; 289: 3243-53.

15. Legemiddelforbruket i Norge. http://www. legemiddelforbruk.no (29.8.2011).

16. Zahl PH, Mæhlen J, Welch HG. Breast cancer overdiagnosis with screening mammography reply. Arch Intern Med 2009; 169: 1000-1.

17. Ernster VL, Barclay J. Increases in ductal carcinoma in situ (DCIS) of the breast in relation to mammography: a dilemma. J Natl Cancer Inst Monogr 1997: nr. 22: 151-6.

18. Weedon-Fekjær H, Lindqvist BH, Vatten LJ et al. Breast cancer tumor growth estimated through mammography screening data. Breast Cancer Res 2008; 10: R41

19. Fryback DG, Stout NK, Rosenberg MA et al. The Wisconsin breast cancer epidemiology simulation model. J Natl Cancer Inst Monogr 2006; 2006 $37-47$

Mottatt 8.2. 2011, første revisjon innsendt 30.8. 2011, godkjent 17.11. 2011. Medisinsk redaktør Are Brean. 